\title{
Aversive Stimulus
}

National Cancer Institute

\section{Source}

National Cancer Institute. Aversive Stimulus. NCI Thesaurus. Code C41257.

A stimulus causing an organism to behave so as to minimize exposure to it (as in negative reinforcement or punishment procedures). 